\title{
The University of Salford Sound of Laughter Project
}

Main author: Wilkie, lan (Lecturer in Performance, University of Salford)

Corresponding authors: Harrison, Luke; Brennan, Dualta; Briggs Hannah; Battle, Lee (c/o

Performance, English and Creative Writing Directorate, University of Salford)

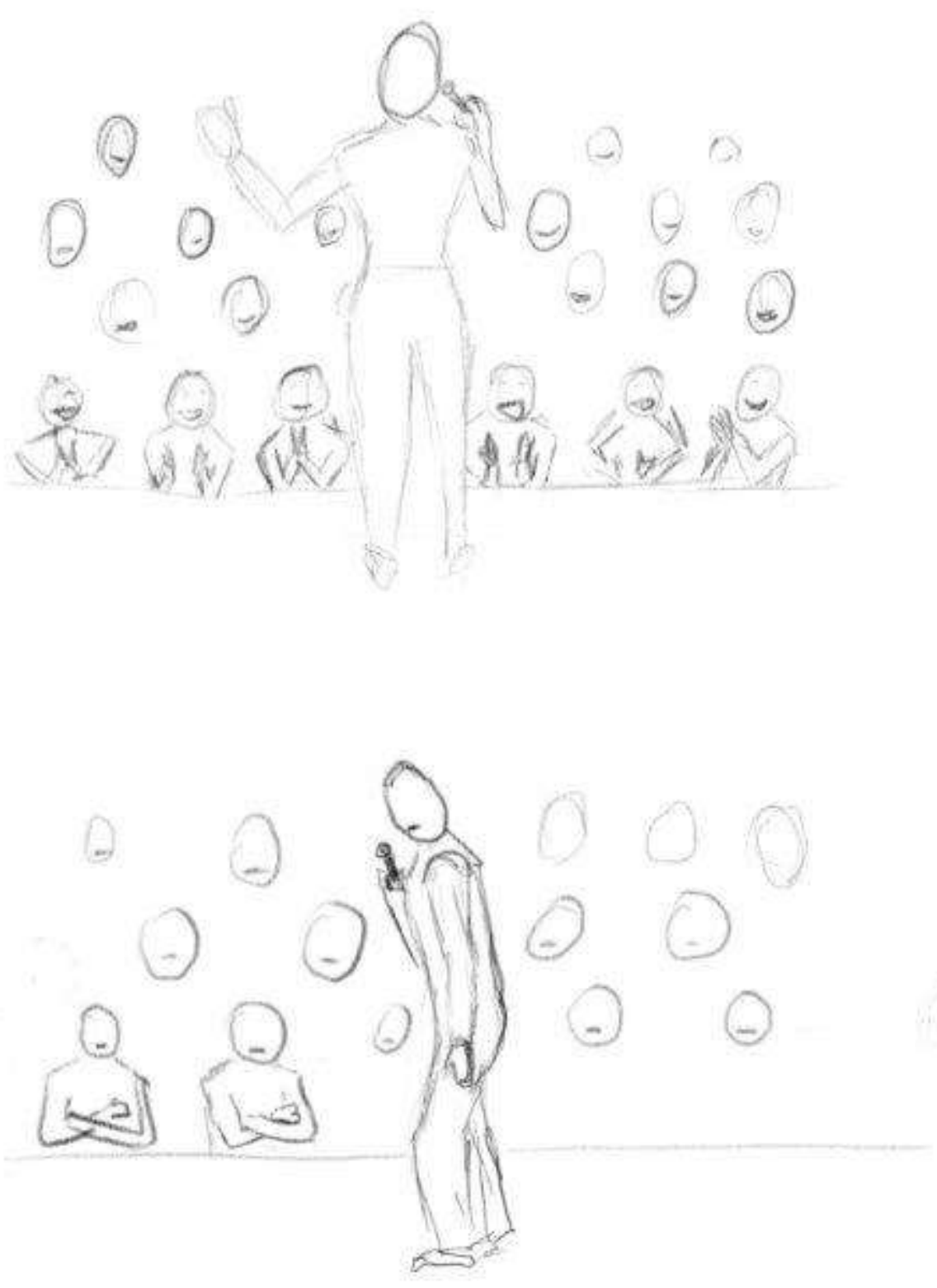

Fig 1: @ Gordon McKendrick (2018) 


\begin{abstract}
What follows is a report of the University of Salford's Sound of Laughter Project (2018). This pilot study was set up as an initial attempt to ascertain whether it is possible to discern any meaning from the different laughter sounds that audiences might make during a stand-up comedy show. The experiment also aimed to discover whether comedians can recognise variations in the properties of laughter responses made during the act of public joking. Further, the study aimed to establish whether performers can discern these different audience laughter sounds in real time and use them as identifiable 'cues' to check the efficacy (or otherwise) of their comic communication. This combined report on the pilot study has been prepared by a group of researchers at the University of Salford, all of which were involved in different stages of the experiment and whose initials are appended to each relevant section of the report.
\end{abstract}

Keywords: Audience laughter; stand-up comedy; joking; psychoacoustics, audience response

\title{
Context to Study (IW)
}

Through a...process we must always try...to scan what is occurring in the audience....and... how I can communicate with them (Joseph Beuys 1970:168)

Beuys' quote above refers to pedagogy and visual/performance art (two fields which share considerable synergies with stand-up comedy). The practice of live comedy, as a didactic art form, is uniquely predicated on spectator response, being specifically reliant on the presence of group laughter for it to be recognisable as a phenomenon. Arguably, group laughter acts as a barometer for stand-up exponents to be able to gauge whether the delivery of their comic material is working or not. As the comic writer and actor Eric Sykes noted, 'it is always difficult to assess the success of a comedy when it is greeted with stony silence' (2005:368). The communal laughter response is, thus, integral to the activity of live public joking. Comedians have, seemingly, always been self reflective on the efficacy of their comedy as it is measurable through the laughter response. According to the film critic James Agee, early film comedians (emerging from Vaudeville) divided their audiences' laughter 
'into four categories in ascending order of hilarity; the titter, the yowl, the belly laugh, and the boffo' (in Palmer: 1987:101). More recently, the playwright Patrick Marber referred in interview to his time as a stand-up comic and how he developed an ear for 'the difference between a proper laugh, a rhythm laugh and a cheap laugh' (2017:37). Comedians using topical material can sometimes be heard to articulate phrases such as "too soon?" in response to audience laughter on occasions where the quality of the laughter reaction audibly contains a quality of shock in response to an allusion they have made. Other comedians might make a point of admonishing their audiences for 'inappropriate' sounding laughter e.g. Frankie Howerd's "no, don't" and "shut your faces". This awareness of different laughter variations and qualities in the laughter response would seem to indicate that practitioners of comedy can differentiate between types of communal laughter and intuit what these differences mean for the reception of their joking.

As Mcllvenny et al note in their linguistic analysis of the phenomenon, 'a live comedy show can best be described as consisting of a rich interaction between comedian and audience, in which the comedian's talk and the variety of audience responses are intricately woven' (1993:239). Previous work, moreover, posits that audience laughter is a predominantly communal activity (Cook, 1994:248) - as anyone who, in contrast, has experienced the embarrassment of laughing alone within a non-theatrical public space might corroborate. Studies on laughter have tended to concentrate on the reasons why individuals laugh or how we use laughter as a socially communicative tool (Scott, 2016:87; Provine, 2016:1536). Laughter has tended to be considered as, essentially, a human intercommunication device, in which it is treated as a linguistic-like, referential signal that can provide meaning about laugher state to the listener (Grammer \& Eibl-Eibesfeldt (1990); Bachorowski et al:2001). However, as Provine also notes, laughter as a consciously induced communal response to performance has its own existential status:

A successful comedian must be attentive to audience cues that govern timing - the audience must be given an interval in which to laugh or applaud ...Audience feedback also influences pacing and the selection of improvised material...successful comedy cannot be done in a vacuum (2000:138-9).

The Salford Laughter Project was an attempt to extend knowledge of the laughter phenomenon from being purely a psychological, physiological, linguistic and individual 
response and to reassess it as a systematic series of cause and effect coactions made between the actor/comedian, acting as the 'multi-channelled transmitter-in-chief...the main agent of transcodification' (Elam, 1994:85) and the audience as 'the spectator...engaged in a project of creative collaboration' (Aston and Savona, 1991:160). In this latter respect, as Provine suggests, comedian and audience are operating in 'dual processing mode' (2000:38) and for the purposes of this experiment, this state informs whether performers might be able to assess the meaning of different 'types' of audience laughter and, by extension, react to any inherent significations that these variations in laughter might manifest.

It was clear from the outset that any one-off experiment was unlikely to yield much in the way of valid results. Too many variables exist in terms of what constitutes an 'audience', let alone whether factors such as the location of the show, the timing of the event, or whether the audience have partaken of some alcohol etc. can affect any potential results. Initial advice from members of the university's Psychoacoustics Department suggested that, using available scientific methods, the most that might be achievable in an experiment of this design was that level, length and timing of the audience's laughter would be as much as could reasonably be expected to be captured. This could possibly be equated to Adami et al's prior study on the density of applause sounds (2017). Nevertheless, it was felt that something relevant might be discovered along the way and that it was worth the attempt potentially to add to the under-researched area of knowledge of the specifics of group laughter. In recording and measuring the different acoustic qualities of group laughter, the experiment was intended to build on Bachorowski et al's prior research into hypothesized differences between affect-inducing, direct and indirect effects, as well as the functional importance of voiced and unvoiced laughter, which, as they note, warrants more detailed empirical testing (2001:1581,1595).

So, for the pilot study, four comedians (Tony Wright, James Allen, Kate McCabe and James Meehan) were asked to perform tried-and-tested material in ten minute sets within the framework of a comedy event that took place in the Studio Theatre in the New Adelphi Building at the University of Salford on $31^{\text {st }}$ January 2018. The routines were recorded along with the audiences' response. Subsequent to an analysis of the recorded data, the four comics were invited back for interview and asked to evaluate the audiences' response and 
to review what reactions they had expected and reassess their practice in the light of the responses they had received. The participants were also asked whether their own material and delivery had altered in live time, given the laughter responses they had received. During the recorded event, drawing from pre-practiced material, all four comedians tended to utilise the well-established format as suggested by Mcllvenny et al:

In the stand-up comedy show a comedian may on many occasions use a membership category to involve the audience in identifying, affiliating or disaffiliating with such a category, usually with some explicit response. Then a comedian can build humour on the knowledge available through the membership category; either making favourable or unfavourable references (1993:239).

All adopted a predominantly anecdotal approach on the night, telling stories apparently drawn from identifiable personal experiences (e.g. being racially stereotyped, being mistaken for someone else of a different gender, visiting a local nightclub, flatmate problems, family relationships, love-making embarrassments etc.). The majority of this material was prefigured with a predominantly university student audience in mind. The sets generally relied on self deprecating twists and often utilised verbally arresting peaks or punch-lines (e.g. "Warrington - it is a shithole"; "peed into a houseplant"; "it stank": "like a dolphin on top of the water"; "nobody likes veg" etc.).

What follows is a series of short reports on the various stages of the pilot study from members of the project team. Below, details of the event management, technical design, interview findings and an audience perspective element are incorporated.

\section{Promotion of Event Report_(HB)}

My main intention in advertising the Sound of Laughter project (promoted under the name Sal'for' Laughs) was to reach as many people as possible through a variety of University channels. I aimed to promote the event to both students and staff alike. I promoted Sal'for' Laughs through various channels, such as the Student Union, the Student Channel, the School of Arts and Media, as a Blackboard (the University's virtual learning environment) announcement, and as a poster uploaded onto the screens around the New Adelphi. Some 
either did not respond or responded too late (such as the Student Union and the School of Arts and Media), but others helped to promote the event on time.

First, a Blackboard announcement was sent out on Blackboard but also over email. The email announcement was sent out to all staff and students in the Arts and Media school. This had the greatest effect on ticket sales, as at least 30\% of Sal'for' Laugh's' tickets were shifted by this alone. It therefore indicated a mix of students and staff in the audience. Secondly, adverts were uploaded to the New Adelphi screens across the building. This gave the event a lot more exposure to a variety of demographics, including students, staff and lecturers, and also accounted for the uptake of more tickets. Finally, the Student Channel promoted Sal'for' Laughs with an article. This sold the remainder of the tickets purely to students, and ensured that the show sold out. Overall, this variety of publicity managed to attract a diverse array of people across the University, primarily students.

The adverts I created for Sal'for' Laughs promoted it as only a general comedy night, without mention of the Sound of Laughter project or the research it would be gathering. However a few advertising channels, such as the Student Channel and the main University news channel, reported Sal'for' Laughs as an experiment looking at the science of laughter. As this was the minority of publicity, it could be assumed that most of the audience who attended Sal'for' Laughs would not be aware of its research element. Another important observation about the promotion was emphasising that the tickets were free. This also encouraged audience numbers.

Observations about our audience demographic could also be made by looking through the ticket list, once the show had been sold out. Many tickets were booked under the name of one of the show's comedians, suggesting that many of the audience were friends or family of the performers. This would give extra incentive for these audience members to enjoy the event, or one comedian in particular.

In conclusion, from the channels of promotion used, the majority of the audience for Sal'for' Laughs were students, as well as some staff. From this audience, it is expected that very few would be aware that the event was for research purposes. There was heightened appeal as 
the tickets were free, although this might have lessened pressure to enjoy the show. And finally, a portion of the audience came particularly for one of the acts as a family/friend, so might have felt an extra incentive to enjoy the show.

\section{Technical Considerations (LH)}

The audio recording of the comedy event had four key criteria of achievement. The final recorded audio was required to:

a) Provide a general capture of the event for archival and video purposes

b) Collect an accurate recording of both audience and performer to time audience response to comedian and comedian response to audience laughter

c) Capture detailed data of the audience laughter for use in analysis

d) Provide a 360 degree 'comedian perspective' ambisonic recording for future research development.

The recording process also had to be detailed enough to be repeatable for future events for comparable recordings to be made.

The event took place in the Studio Theatre of the New Adelphi Building at the University of Salford, Greater Manchester, UK. The recording was taken from the theatre's Midas M32R mixing console, acting as both a live mixer and audio interface for a Macbook Pro recording into Adobe Audition at $48 \mathrm{khz} / 24 \mathrm{bit}$ recording rates. All recordings were taken as post gain direct outs.

Microphones Used:

4x Schoeps 'Collette' CMC MK4 microphones

1x Sennheiser Ambeo VR Microphone

2x Sennheiser SM58 Microphones

Additionally 1 stereo DI feed was taken from a Rode RD-300 Stage Piano for the musical acts.

The 4 Schoeps microphones were chosen for their cardioid polar pattern and flat frequency response, rejecting reflecting from the lighting rig from which the microphones were 
suspended and capturing direct sound from the audience. They were suspended at 3 metres from the floor and equidistant from one another. The estimated audience size was 90, though was not guaranteed. The microphones were positioned strategically over intersections of the thirds of the seating rows, with 2 microphones covering 3 rear rows of seating and 2 microphones covering 2 front rows of seating (Fig Y). Each pair of microphones was 2 metres away from each other on the width of the seating, with the front and rear distance being 1 metre. This allowed for a reliable capture dependant on eventual size of audience and how that audience chose to place themselves in the seating area.

The Sennheiser Ambeo mic was placed front and centre of the stage area, facing the audience. The primary function of this microphone was to record the audience from the perspective of the comedian, though the advantage of the spherical nature of this microphone is that it also captured the ambience of the performance, for the general capture of the evening.

The artists used the two SM58 microphones as performance mics which played out to the central PA in the room. A recording of these microphones was taken to assure clarity of the acts speech when mixing down to a final product for video or audio playback.

As with many live recordings of this nature, there was no time to set the gain levels for each microphone accurately until the audience were in the room and responding to the comedians. This meant the recording of the beginning of the performance has some discrepancies in gain levels as they were adjusted. Extensive notes were taken should this be a problem at the mix stage, though the beginning acts (sketch-based comedy) were essentially 'warm ups' so it is likely that this will not be an issue. The Sennheiser Ambeo microphone had to be adjusted carefully as it is 4 separate mono feeds in the desk, and the desk had no way of linking the gain channels of 4 microphones. Each pair was stereo linked to adjust 2 channels equally, and the digital gain trim was matched exactly for both pairs to ensure even gain response for each microphone capsule.

The final results were clean audio recordings where required. The details of the audience laughter recordings can be found elsewhere in this report. Using the recordings, timings can 
be measured in software accurate to the millisecond of audience reaction to the comedian. The details of this are beyond the scope of this report, but this data may prove useful in future research. The 360 recording of the piece is only partly successful as a first attempt. The position of the microphone was not quite as effective as desired, as the recording doesn't feel particularly immersive. This is likely due to the microphone being placed between comedian and audience, so is an unnatural place to be placed as a listener. Future work will use this microphone in different positions to determine if it is more effective.

There is also enough recorded audio to produce an overall high quality mix of the performance for underlaying video footage. While there are some vocal pops from the use of handheld mics, this is characteristic of a stand-up performance and so is deemed a natural artefact that is expected in such productions.

Overall, the recording was a success and has met or partially met all the required outcomes.
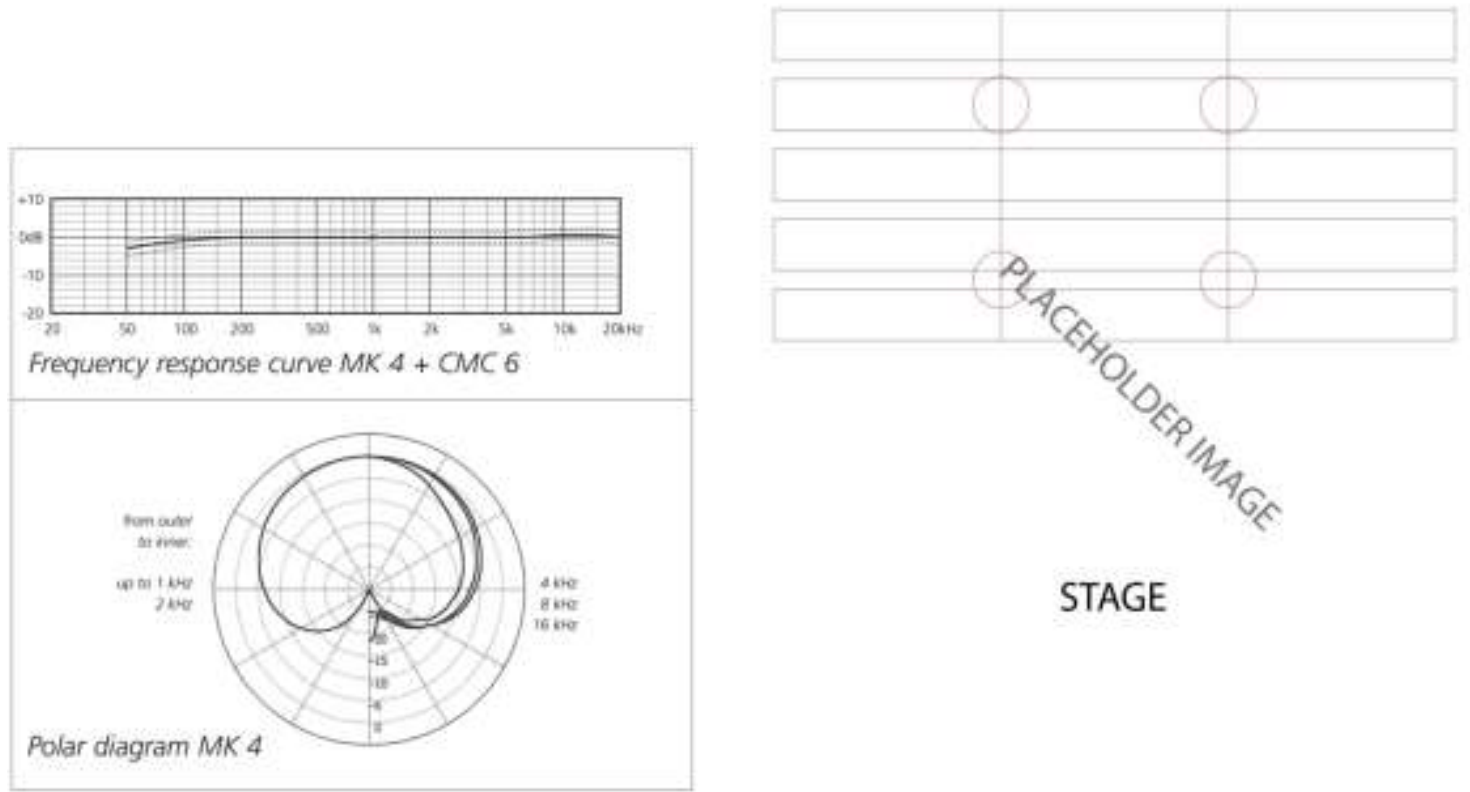

STAGE

Fig 2 @ Luke Harrison (2018) 
Psychoacoustics Elements (DB)

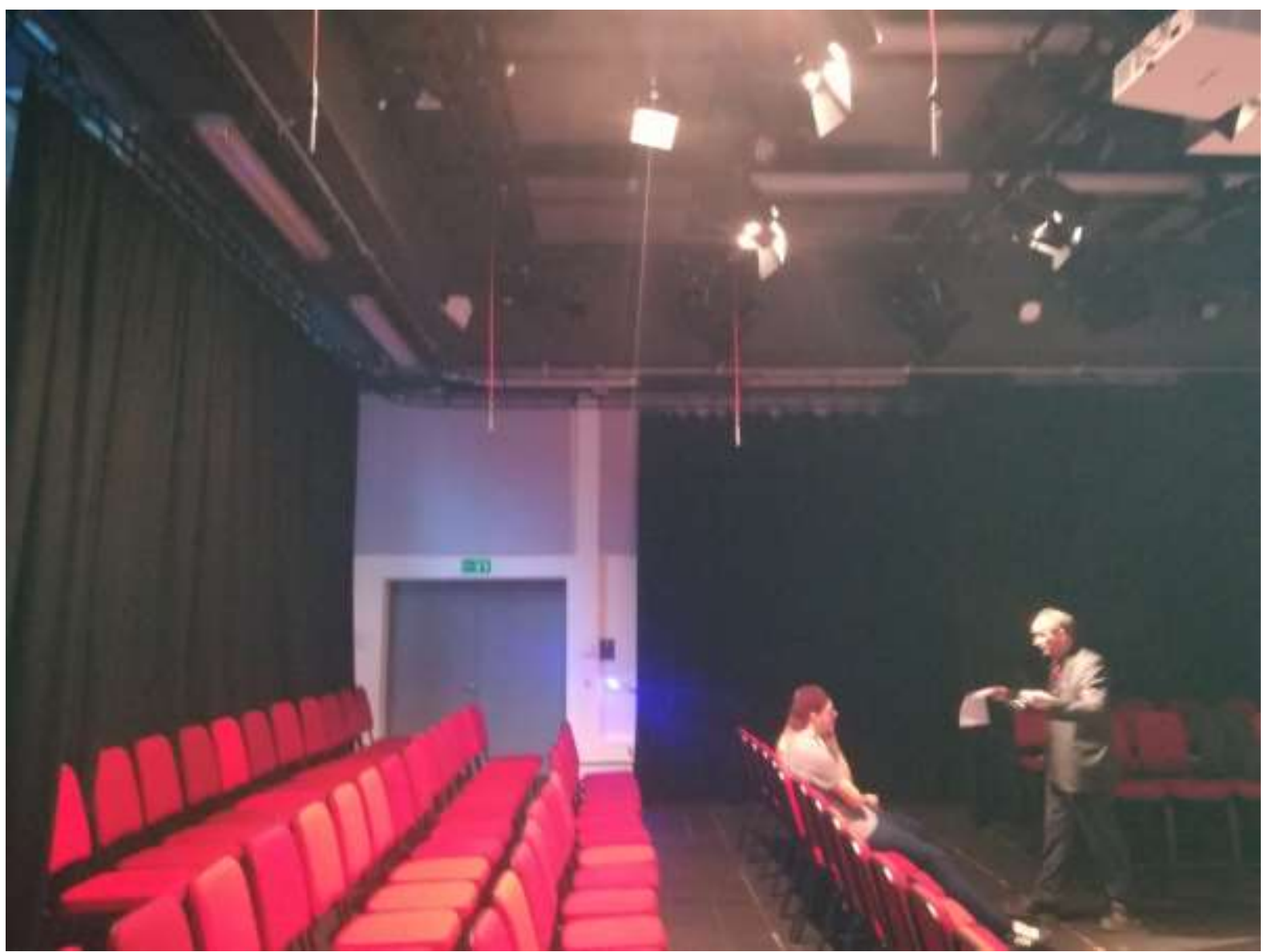

Figure 3. (C) Dualta Brennan. Showing the arrangement of the audience and microphones overhead.

For empirical testing, the acoustic responses were measured in amplitude by using the root mean square (RMS) of each laugh event, the duration, which is the length of laugh event in time, and the chosen average type centroid frequency, which is the physical balance point of a waveform. Conclusions were drawn using ANOVA's and Tukey's tests, which were used to distinguish if genre of joke, comedian or time since the start of the show resulted in any differences between our chosen acoustic responses of RMS - Amplitude, Duration - Length of laugh and Centroid frequency the average frequency. Comedian and time since the start of the show had a significant impact on RMS and Duration of laughter. However, the tests failed to find any differences in the tonal qualities of the laughter, nor did the genre of laugh have any impact on the measured acoustic responses. There was no effect upon centroid frequency but there was upon the other two factors, which suggests that duration and amplitude are good indicators of laughter response, but that centroid frequency is not. Why is this? The centroid frequency is the physical balance point of the waveform and perhaps 
this was not the best variable to select, it is possible that a different average would be better to see differences in the qualities. There was no significant impact whatsoever of genre on any of the acoustic responses. RMS, Duration and centroid all show null results. The reason for this is unknown, but the investigation theorises that, for one mode of analysis, the genre categories were too coarse a classification for the joke type. Perhaps it was also because there are too many variables to take into consideration.

\section{Findings (IW)}

From this incarnation of the study, it might well be concluded that the qualities of laughter cannot properly and scientifically be measured within an experiment of this design. Given then, that no real correlation between cause and effect was able to be discovered through this iteration of the study, was there anything at all to be found regarding the main questions, i.e. discerning meaning from the different laughter sounds that audiences might make during a stand-up comedy show; whether comedians can recognise variations in the properties of laughter responses made during the act of public joking; and, can they, in turn, check these different audience laughter sounds in real time and use them as identifiable 'cues' to discern the efficacy (or otherwise) of their comic communication?

Certainly, the research corroborated that comedians habitually use devices which encourage interactivity between the performer and the audience. Kate McCabe, for instance, used a number of call and response solicitations ("How are you doing?"; "Give me a shout if you are married"; "Did you guys know that?"; and "Are you guys coffee drinkers?" She appropriated a "knock knock" joke format at the end of her routine to cement the call and response relationship. In a subsequent interview, and after hearing back the recording of the event complete with audience response, McCabe agreed that she was "conscious of call and response as something to keep the attention of an audience by including them...to refocus energy and show confidence i.e. 'I can deal with your answer'... [these act as] invitations [and] keep the audience alert... [in] a two-way street". She described the process of awareness of, and reaction to, the audience's response as "surfing". 
Another example of audience/performer intercommunication in action occurred (perhaps counter-intuitively) in James Allen's multiple uses of pauses. As Gruber notes, 'the performance of a comedy...necessitates frequent pauses for the audience to laugh' (1986:132). In the live stand up situation, as well as allowing monitoring of the audience response, the use of pauses can also be seen to signify some kind of meaningful intercommunication between the performer and the audience. The dictionary definition of a pause is 'an interval of inaction...a break in speaking or action' (Pearsall and Trumble, 1996:1066) i.e. apparently 'dead air' that, in the course of a performance, can only become significant in context where the performer intentionally means the pause to facilitate a desired reaction. Here, the practice of a pause assumes a specific, meaning making role that is dependent on both the situation and the performer/spectator intercommunication of the non-verbal signal. The dramatist Harold Pinter's famous use of the 'Pinteresque pause', has, for instance, become widely redolent of 'subtextual', unspoken, 'deeper' meanings. Pinter himself referred to the 'silences' in his plays as 'the thing known and unspoken...a language.... where under what is said, another thing is being said.....we communicate only too well, in our silence, in what is unsaid...' (1981:13-15). In comedy, use of the pause for the purpose of eliciting laughter (and its concomitant manifestation of a cause and effect mechanism) can be discerned in the use of the pause as a peculiar means of signification that might be said to illustrate - in microcosm - an aspect of Jacques Derrida's notion of 'differance' - i.e. 'the gap between what a person speaks or writes and how that discourse is understood by its audience. The emphasis is on the gap and not the reception' (in Hussey, 2010:32). Allen himself, reflected on his multiple use of pauses as being "not conscious... [although] I am probably reflective during the pauses if I'm on a ride with the audience...They sense safe hands here... and it helps the conversational nature of the routine".

One piece of interesting data that correlated most closely to the central research question regarding the laughter interaction between stand-up comedian and audience and back again, occurred during James Meehan's set. This comedian, whose routine provided the final, headline act, typically utilised a number of 'membership category' (Mcllvenny, Mettovaara and Tapio, 1993:239) references throughout his set. He also deliberately incited the audience to 'practice' laughter at the beginning of his routine, starting this interaction 
by asking them "are you alright, it all seems very low key"? The opening of Meehan's act established membership links in his introduction of jokes about his family, class, sexuality, and his history as a roadie for tribute bands. Meehan also used call and response devices and also included a participatory knock knock formulation as part of his direct audience interactivity strategy. At various points he used a call and response device, e.g. "give me a cheer if you've got Netflix". In directly quantifying the audience's response in this manner, Meehan was further undergoing Mcllvenny et al's process of measuring within 'the only immediate way in which a performer can test, gauge and establish audience approval' (1993:230).

Towards the end of his set, Meehan went on to tell an extended joke based on an extract from an Adam Sandler film (Click: Coraci, 2006). The set-piece concerned what Meehan would do if he, too, could 'pause time'. The 'what I would do if I could pause time' routine relied on an elaborate, repetitive series of ludicrous, yet, internally logical suggestions as to how Meehan would interfere with the time sequence of someone in the act of going up and down a ladder. The routine ended with the punch-line articulation "classic prank". In this joking act, it was apparent that the audience's laughter was clearly exponential in building a cause and effect response within the comic communication. As DB notes of this interaction in his psychoacoustic report,

whilst not being as significant as the RMS values, the duration of laughter got progressively longer and there was an extreme outlier of a 40 second laugh right at the end of the show... The outlier was in fact due to the comedian himself who had a joke that drip-fed the information to the audience slowly and built into a laugh crescendo.

It is clear that Meehan consciously adjusts his timing and delivery in accordance with the audience's response during this section. The way the build morphs and Meehan's apparent "surfing" on the audience's laughter during this portion of the act appears to offer some evidence of an instance of a comedian discerning meaning from the different laughter sound qualities that an audience makes during a stand-up comedy show.

Moreover, the question of whether comedians can recognise variations in the properties of laughter responses made during the act of public joking, and whether they, in turn, can discern these different audience laughter sounds in real time and use them as identifiable 
'cues' to check the efficacy (or otherwise) of their comic communication is partly supported by what might be termed a 'subconscious articulation' uttered by Meehan. At the conclusion of this set-piece, Meehan articulated the word "good!" This utterance appeared to stand alone and appeared to be made in response to how effectively the routine had clearly been transmitted and received. The subconscious articulation of the word "good" seemed to suggest that Meehan was wholly aware of the audience's reaction and that the utterance was a spontaneous comment which expressed acknowledgment of his satisfaction with the quality of the laughter he had received.

In interview, upon hearing this example, Meehan reported that while he had not been consciously aware of saying the word 'good' as a comment on the audience's response, he observed that the comedian needs to be "in control in time...attuned...needs to be in the moment [to keep the audience's] confidence and trust". He also opined that in saying the word "good" he might have been "paying audience a compliment... [i.e.] why haven't you been doing that all night?" This example indicates an occasion of live 'transcodification' (Elam, 1994:85) with the audience actively 'engaged in a project of creative collaboration' (Aston and Savona, 1991:160) through their laughter which, in turn, provides meaning to the comedian.

\section{Audience Perspective (LB)}

This brief report considers my role as an observer-participant in the Sal'for Laughs sound of laughter comedy project, offering an account of my experience spectating as a quasiresearcher, and reflecting on the positioning of the audience in the initial pilot study in order to inform any future iterations of this event.

My involvement in this project concerns an interest in audience perspectives and reactions. During the performance, I was positioned in the audience wearing a (small but highly visible) GoPro camera in an attempt to capture the performance from the point of view of the spectator.

Owing to both the physical sensation of the headcam and the acknowledgment of it from various other audience members seated around me, I felt unable to watch the performance 
freely and impartially; I remained almost entirely aware of my own position, self-conscious of my own physical and audible reactions, and ultimately somewhat removed from the performance event itself. There were, however, certain moments of total engagement in the performance, after which I would again become conscious of my own situation. These moments of 'escapism' typically occurred during what was, for me, the funniest comedy, and this tended to correlate with the moments that elicited the most laughter in the room; for the most part, though, awareness of the recording camera redirected my attentions and inhibited my responses.

The captured footage also demonstrates an otherwise unconscious attempt to capture the reactions and movements of other spectators throughout the auditorium, as opposed to the performing acts themselves. The heightened consciousness caused by the camera resulted in my becoming more of an active researcher engaged in the audience, as opposed to an audience member engaged in the performance, which furthers any possible self-awareness inherent in a spectator knowing the research aims of the project.

Despite disclosures made on advertising materials in the interests of ethical research practice, however, it became apparent from the audience response questionnaires that the majority of spectators were unaware that the performance was actually part of an active research project. It might therefore be interesting to consider whether or not knowledge of the research element, and in particular their participatory role as (anonymous) laughterrecorded subjects, would alter the meaning of the performance for individual members of the audience, and possibly affect their behaviour and reactions when responding to the comedy.

Based on my own experience, I would certainly expect this to be the case, and while further research would be needed to explore this empirically, it would be my recommendation that if the project is to be repeated, participants should be unaware of the exact purpose of the research wherever possible in the interests of preserving authenticity in their responses.

Further to this, the visibility of other professional camera equipment and operators around the auditorium may also problematize the legitimacy of the collective audience response. 
Although the recording of live performance events is now rather commonplace, the presence of camera equipment in relative close proximity to the spectators, together with the conspicuousness of my own head camera, adds further awareness of the event as one which is being recorded, and could therefore possibly impact (by inhibiting or potentially exaggerating) audience members' reactions.

Furthermore, the awareness of the recording activity is evident in the performers themselves too, who often look directly at the lens of the camera. If knowledge of and active participation in the event can produce awareness of context over content in spectators, it might also affect the performers themselves with a double awareness of self and event beyond that of their usual performer-audience response sensitivity. It would also be recommended, then, that the performers, while made aware of the event's nature as a research project, remain uninformed of the exact purpose of the research (the recording and subsequent analysis of laughter itself) enabling them to focus on simply making people laugh without performing the dual role of data-collectors, in order to minimize the impact of the in-built in-the-moment laughter analysis processes utilised by comedians.

\section{Conclusions (IW)}

Given that results from this initial experiment are largely inconclusive, speculative and purely qualitative in nature, any further experimentation into audience laughter would require a much more formal design in regards to validity, study population and sampling, data collection methods and instruments, data analysis methods, participants in the study, and ethical considerations.

One suggestion for a future iteration might be to establish a longitudinal study in which a touring comedian's set could be sequentially recorded at different venues and any contrasts in the different audiences' reactions could be mapped, contrasted and compared. Different audience responses to (effectively) the same material but with conditional variations might make for a more sustainable and scientifically rigorous study.

In the meantime, we offer these initial findings from this pilot study as a starting point for what, hopefully, could prove to be a richly unique study into a hitherto unexplored and 
under researched theme - that of the comedian's reflexive activation of communal audience laughter.

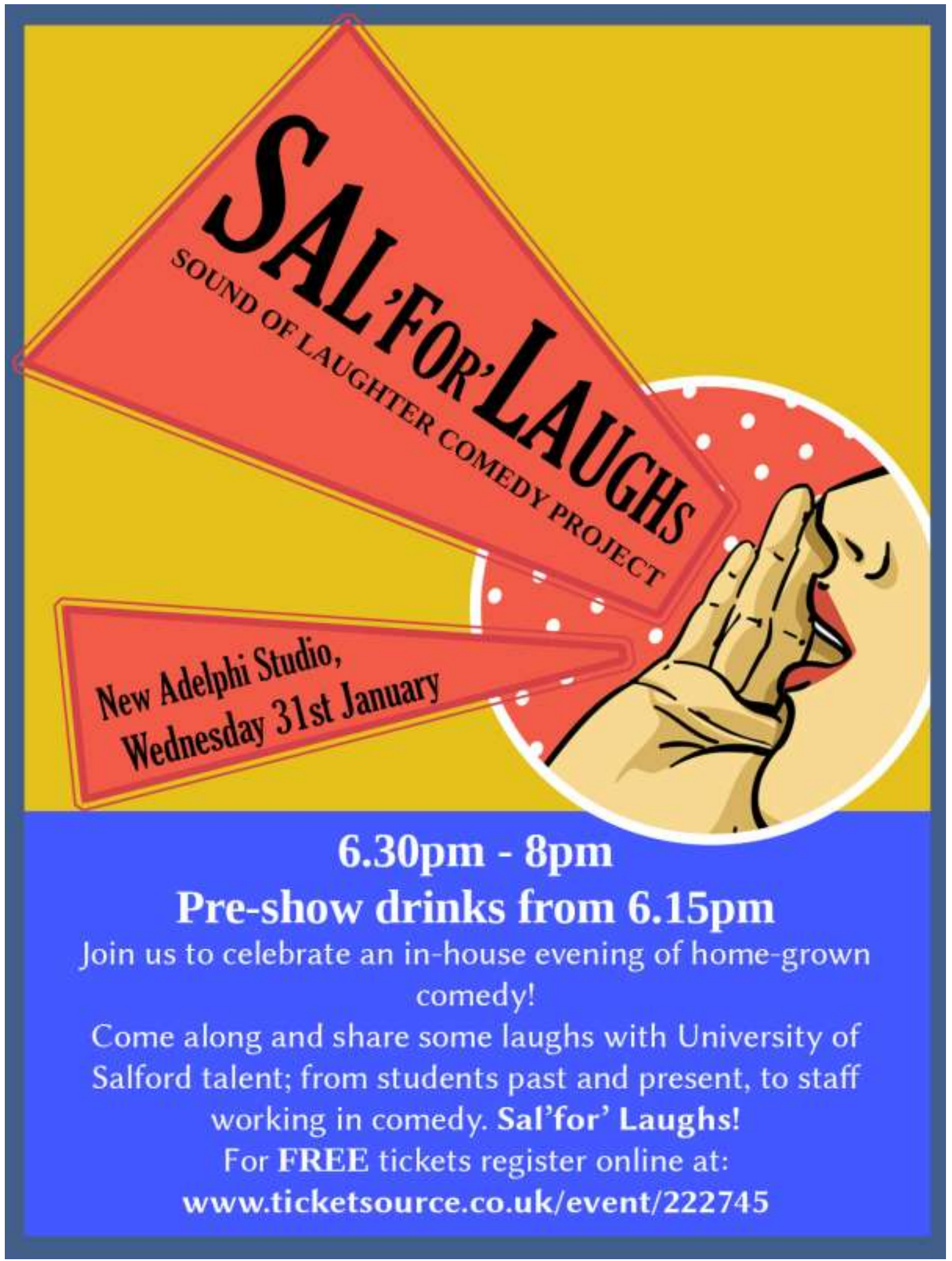

Fig 4 (C) Hannah Briggs (2018) 


\section{Audience Statistics}

Audience survey details: 24 demographical responses from a total of 42 attendees were obtained. Only 6 respondents realised it was part of a research project. 7 were female 15-25 year olds, 11 were male. 6 staff/older $(3 \mathrm{~m}, 3 \mathrm{f}$ ) responded to the questionnaire. A mixed prior attendance at stand-up comedy was noted.

\section{Acknowledgements}

Special thanks to James Allen, Kate McCabe, James Meehan and Tony Wright for their participation in this study. Our thanks too to The Salford Comedy Players, Hannah Dunstall, Tommy King and Lukas Kirkby for supplying supporting comedy on the night. To Michelle Morris for the visual recording and documentary of the project; to Professor Trevor Cox for his initial advice and valuable caveats; and to the School of Arts and Media and Directorate of Performance for the loan of theatre and some funding. Without the help of all these colleagues, this project could not have taken place.

\section{References}

Adami, Alexander; Taghipour, Armin; Jurgen, Herre (2017) On Similarity and Density of Applause Sounds. JAES Volume 65 Issue 11, pp. 897-913.

Agee, James (1963), 'Comedy's Greatest Era' in Agee On Film v.1, London: Peter Owen.

Aston, Elaine and Savona, George, (1991) Theatre as Sign-System: A Semiotics of Text and Performance, London: Routledge

Bachorowski, J.-A., Smoski, M.J., \& Owren, M.J. The acoustic features of human laughter. Journal of the Acoustical Society of America, 110 (1581) 2001, pp 1581-1597.

Beuys, Joseph (1970) in Filiou, Robert, Teaching and Learning as Performing Arts, Verlag Gebr. Koenig, Koln- New York.

Cook, William (1994), Ha Bloody Ha: Comedians Talking, London: Fourth Estate.

Elam, Keir (1994), The Semiotics of Theatre and Drama, London: Routledge. 
Grammer, K., and Eibl-Eibesfeldt, I. (1990). 'The ritualization of laughter', in Naturlichkeit der Sprache und der Kultur: Acta colloquii, edited by W. Koch (Brockmeyer, Bochum, Germany), pp. 192-214.

Gruber, William (1986), Comic Theaters, Athens: Uni of Georgia.

Hussey, Andrew (2010), "Stories of a Serious Man". Review of Mikics, David (2010) Who Was Jacques Derrida? An Intellectual Biography, The Independent newspaper, 09/4/2010.

Marber, Patrick (2017) 'I feel like the same idiot worrying "what is this nonsense?"' Evening Standard, 02/02/2017

Mcllvenny, Paul, Mettovaara, Sari and Tapio, Ritva (1993), 'I Really Wanna Make You Laugh: Stand-Up Comedy and Audience Response'. In Suojanen, Matti K. and Kulkki-Nieminen (eds.) (1993) Folia, Femistica \& Linguistica: Proceedings of the Annual Finnish Linguistics Symposium, May 1992, Tampere University Finnish and General Linguistics Dept.

Publications 16.

Pearsall, Judy and Trumble, Bill (1996), The Oxford English Reference Dictionary, Oxford: O.U.P.

Pinter, Harold (1981), 'Writing for the Theatre', Introduction to Harold Pinter: Plays: One, London: Methuen.

Provine, R. (2000) Laughter: A Scientific Investigation, London: Penguin.

Provine, R. (2016) 'Laughter as a Scientific Problem: An Adventure in Sidewalk Neuroscience', The Journal of Comparative Neurology 524: 1532-1539

Scott, Sophie (2016). 'Why do humans laugh?' Interview with Nigel Warburton in New Philosopher Magazine, Tasmania: Poet Press

Sykes, Eric (2005) If I Don't Write It, Nobody Will London: Fourth Estate

\section{Author Contact Details:}

Dr lan Wilkie

Lecturer In Performance; Editor Comedy Studies / School of Arts and Media Address Room 6:02, New Adelphi Building, University of Salford, Manchester M5 4BR T: +44(0) 01612955554

email I.Wilkie1@salford.ac.uk / www.salford.ac.uk

Luke Harrison

LUKE HARRISON (MSc, FHEA)

Lecturer in Sound for Live \& Recorded Media Performance

6.02, New Adelphi Building, Salford, M5 4BR

T: +44(0) 01612956013 I.a.harrison@salford.ac.uk / www.salford.ac.uk 
Dualta Brennan

BSc Professional Sound and Video Technology

d.brennan1@edu.salford.ac.uk

Hannah Briggs

Arts Associate / School of Arts \& Media

6.47 / New Adelphi Building / University of Salford / M5 4BR

T: 01612952533

h.c.briggs@salford.ac.uk / www.salford.ac.uk

Lee Battle

Lecturer in Media and Performance

Room 6.02 | New Adelphi Building

School of Arts \& Media

University of Salford

I.w.j.battle@salford.ac.uk

www.salford.ac.uk 